\title{
Влияние отжига в инертной атмосфере на электрические свойства кристаллических пленок пентацена
}

\author{
(ㄷ Г.А. Юрасик, А.А. Кулишов, М.Е. Гиваргизов, В.А. Постников \\ Федеральный научно-исследовательский центр „Кристаллография и фотоника“ РАН, Москва, Россия \\ E-mail: yurasik.georgy@yandex.ru \\ 『E-mail: postva@yandex.ru
}

Поступило в Редакцию 4 августа 2021 г.

В окончательной редакции 27 августа 2021 r.

Принято к публикации 30 августа 2021 г.

\begin{abstract}
Представлены результаты исследования влияния отжига при $150^{\circ} \mathrm{C}$ в инертной атмосфере $\left(\mathrm{Ar}+5 \% \mathrm{H}_{2}\right)$ на электрические свойства органических полевых транзисторов на основе пентацена. Кристаллические пленки пентацена толщиной $95 \pm 5 \mathrm{~nm}$ были получены с помощью вакуумного термического напыления. Исследованы передаточные и выходные характеристики полевых транзисторов до и после отжига в течение $15 \mathrm{~h}$. Установлено, что в результате термической обработки дырочная подвижность в режиме насыщения увеличилась в среднем на $30 \%$, а пороговое напряжение уменьшилось приблизительно в 2 раза. По данным атомно-силовой микроскопии отжиг привел к снижению шероховатости поверхности пленок пентацена более чем в 2 раза, а также к заметному укрупнению зерен, что и привело к уменьшению концентрации ловушек для дырочного электротранспорта в канале полевого транзистора.
\end{abstract}

Ключевые слова: пентацен, вакуумное термическое напыление, кристаллические пленки, органические полевые транзисторы, дырочная подвижность, отжиг в инертной атмосфере.

DOI: 10.21883/PJTF.2021.23.51783.18983

Для оптоэлектроники получение тонких кристаллических пленок на подложках как органических, так и неорганических полупроводников с помощью вакуумного термического напыления давно уже является классическим методом, отличающимся простотой и эффективностью $[1,2]$. Вместе с тем полученные таким образом тонкопленочные кристаллические структуры, как правило, отличаются невысоким структурным совершенством, поскольку представляют собой поликристаллы с размерами зерен на уровне сотен нанометров. Один из возможных путей улучшения морфологического качества напыленных пленок с целью улучшения электрических свойств - постобработка в условиях изотермического отжига при повышенной температуре. Такой подход весьма эффективен для изначально аморфных пленок, в которых за счет последующего отжига инициируется кристаллизация с образованием крупных монокристаллических областей, что способствует существенному улучшению электрических свойств $[1,3]$. Однако с точки зрения применения данного подхода для улучшения структурного совершенства кристаллических слоев органических полупроводниковых молекул, несклонных к формированию аморфной фазы, в литературе имеются неоднозначные мнения, что, судя по всему, связано с недостатком систематических исследований. Рассмотрим, например, один из наиболее известных и эффективных с точки зрения электрических свойств органических полупроводников - пента- цен $[4,5]$. Авторы работ [6,7] сообщают, что с ростом температуры выдержки, производимой в вакууме в течение $2 \mathrm{~h}$, до $70^{\circ} \mathrm{C}$ наблюдается уменьшение среднего размера зерен и снижение шероховатости поверхности пленок пентацена; при этом подвижность дырочного транспорта в устройстве полевого транзистора при выдержках до $45^{\circ} \mathrm{C}$ увеличивалась, а выше данной температуры уменьшалась. Согласно [8], при выдержке пентаценовых тонкопленочных полевых транзисторов в вакууме в течение $15 \mathrm{~h}$ до $90^{\circ} \mathrm{C}$ наблюдается увеличение среднего размера зерен, а воздействие на дырочную подвижность аналогичное: при выдержках до $50^{\circ} \mathrm{C}$ имеет место увеличение почти в 2 раза, а выше данной температуры - снижение к исходному значению при комнатной температуре. Согласно результатам [9], при выдержке в потоке азота при температурах до $120^{\circ} \mathrm{C}$ отмечаются улучшение кристаллического упорядочения молекул в пленках и улучшение электрических свойств с увеличением дырочной подвижности почти в 4 раза в сравнении с исходными неотожженными пленками, а при температурах от 120 до $240^{\circ} \mathrm{C}$ электрические свойства деградируют. В работе [10] сообщается, что отжиг тонкопленочных полевых транзисторов в азоте при температурах до $180^{\circ} \mathrm{C}$ снижает шероховатость поверхности пленок и значительно улучшает их электрические характеристики. О заметном улучшении электрических характеристик полевых транзисторов после отжига в течение нескольких часов в вакууме при $77^{\circ} \mathrm{C}$ также 

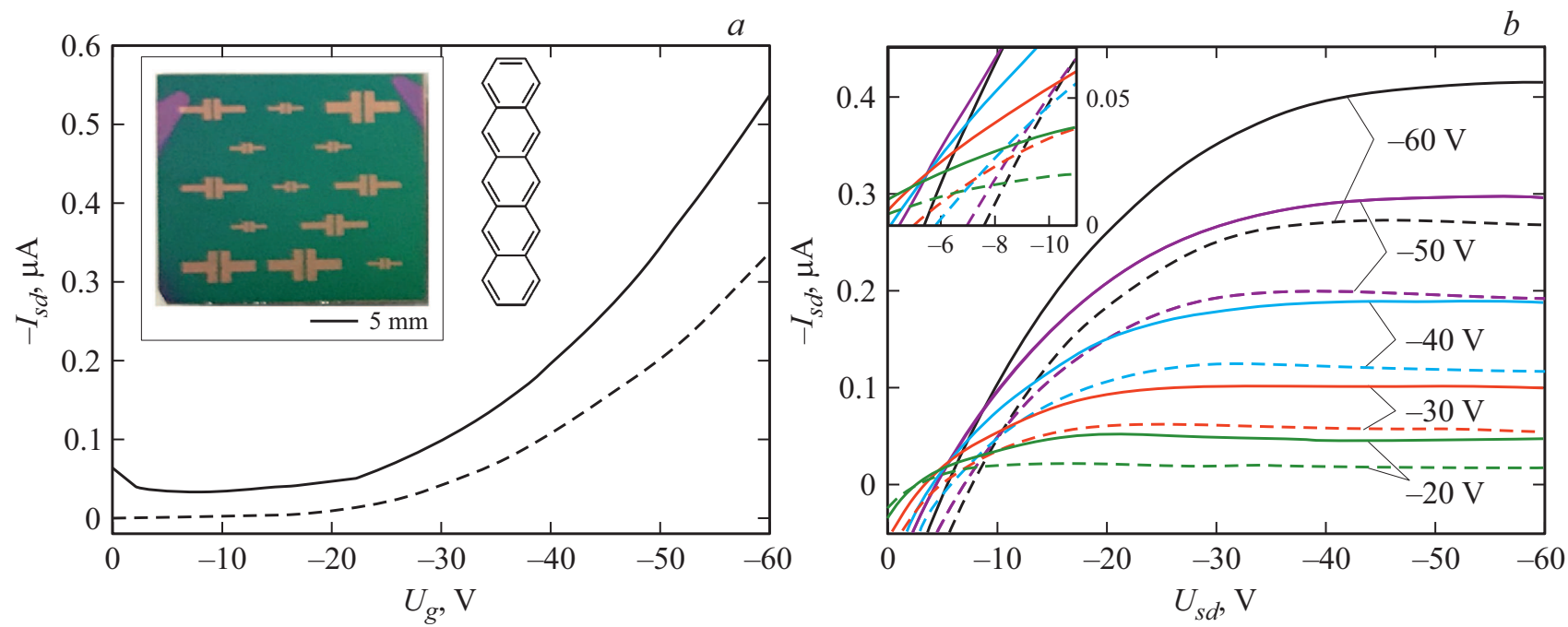

Рис. 1. Вольт-амперные характеристики полевого транзистора до обработки (штриховые кривые) и после отжига при $150^{\circ} \mathrm{C}$ (сплошные кривые). $a$ - передаточные характеристики при напряжении между истоком и стоком $U_{s d}=-60 \mathrm{~V}$. На вставке подложка $p$-Si с образцами ОПТ. $b$ - семейство выходных характеристик при различных значениях напряжения на затворе $U_{g}$. На вставке - зависимости в линейной области.

сообщается в работе [11]. Имеются сведения о том, что при отжиге тонкопленочных полевых транзисторов на воздухе в течение $1 \mathrm{~min}$ наблюдалось заметное улучшение электрических характеристик с максимумом для $77^{\circ} \mathrm{C}$, а выше данной температуры электрические свойства стремительно деградировали [12].

С целью изучения влияния термической обработки на морфологическое и структурное совершенство напыленных тонких кристаллических пленок на основе полупроводниковых органических молекул нами инициированы систематические исследования. В настоящей работе представлены результаты изучения влияния отжига кристаллических пленок пентацена $(\mathrm{Pc})$ в течение $15 \mathrm{~h}$ при $150^{\circ} \mathrm{C}$ в инертной атмосфере. Из литературы известно, что у пентацена около $190^{\circ} \mathrm{C}$ наблюдается полиморфный переход в высокотемпературную кристаллическую модификацию [13], а также интенсифицируются процессы возгонки молекул в паровую фазу [14], что на данном этапе мы хотели бы исключить из рассмотрения. Исследование электрических свойств кристаллических пленок пентацена, как и в представленных выше работах, также было выполнено по методу полевого транзистора $[11,12,15,16]$.

Органические полевые транзисторы (ОПТ) изготавливались по схеме с нижним затвором и верхними истоковыми и стоковыми электродами [15]. В качестве подложек, выполняющих роль электрода затвора, использовались пластины кремния толщиной $0.5 \mathrm{~mm}$, допированного примесью $p$-типа (подложки $p$-Si). Роль подзатворного диэлектрика на подложках $p$-Si выполнял оксидный слой $\mathrm{SiO}_{2}$ толщиной $440 \mathrm{~nm}$, выращенный путем отжига на воздухе при $950^{\circ} \mathrm{C}$. Подготовленные таким образом подложки с одной стороны протравливались концентрированной плавиковой кислотой $(\mathrm{HF})$ для удаления $\mathrm{SiO}_{2}$.
Подложки последовательно очищались с помощью ацетона, изопропанола, деионизованной воды и выдерживались в установке плазменной очистки (Harrick Plasma, США) в течение $0.5 \mathrm{~h}$ при генерации плазмы из атмосферного кислорода. Далее на поверхность подложек со слоем $\mathrm{SiO}_{2}$ была нанесена пленка полиметилметакрилата (РММА) из насыщенного раствора в толуоле с помощью метода центрифугирования со скоростью вращения $3000 \mathrm{rpm}$ на установке Spin Coater P6700 (Specialty Coating Systems, США). Толщина сформированного таким образом буферного слоя РММА составляла $30 \pm 3 \mathrm{~nm}$. Для формирования кристаллических пленок использовался пентацен (99.9\%, Sigma Aldrich) без дополнительной очистки. Напыление Рc, а затем контактов стока и истока из золота $(99.99 \%)$ производилось методом вакуумного термического напыления на установке COVAP III (Angstrom Engineering, Канада), интегрированной в перчаточный инертный бокс СПЕКС ГБ 03М („Спектроскопические системы““, Москва), при давлении в камере $\sim 1 \cdot 10^{-6} \mathrm{mbar}$. Напыление золотых контактов проводилось через специально изготовленные маски (см. вставку на рис. $1, a$ ). Скорость напыления Рс и золотых контактов была 0.8 и $0.2 \AA / \mathrm{s}$ соответственно. В peзультате напыления толщина кристаллической пленки пентацена составляла $95 \pm 5 \mathrm{~nm}$, а золотых контактов $50 \pm 10 \mathrm{~nm}$. В процессе напыления пленок пентацена температура подложек не превышала $25^{\circ} \mathrm{C}$.

Морфология поверхности полученных пленок исследовалась с помощью атомно-силового микроскопа (ACM) Ntegra (NT-MDT, Россия) в режиме полуконтактного метода (зонды серии NSG01 с жесткостью кантилевера $5.1 \mathrm{~N} / \mathrm{m}$, резонансной частотой $103 \mathrm{kHz}$, радиусом закругления иглы не более $10 \mathrm{~nm}$ ), откалиброванного по образцу TGZ1 (NT-MDT). Полученные топограммы об- 
Усредненные электрические характеристики и параметры поверхностной морфологии кристаллических пленок пентацена до и после отжига при $150^{\circ} \mathrm{C}(15 \mathrm{~h})$

\begin{tabular}{c|c|c|c|c}
\hline Обработка & $\mu, 10^{-3} \mathrm{~cm}^{2} \cdot \mathrm{V}^{-1} \cdot \mathrm{s}^{-1}$ & $U_{t}, \mathrm{~V}$ & $R_{a}, \mathrm{~nm}$ & $N_{a}, \mu \mathrm{m}^{-2}$ \\
\hline До отжига & $1.9 \pm 0.3$ & $-16 \pm 2$ & 2.5 & 45 \\
После отжига & $2.5 \pm 0.4$ & $-7 \pm 3$ & 1.1 & 25
\end{tabular}

Пр имечан и е. $\mu$ - дырочная подвижность в режиме насыщения, $U_{t}-$ пороговое напряжение, $R_{a}$ и $N_{a}-$ средние шероховатость поверхности и плотность зерен пленки.
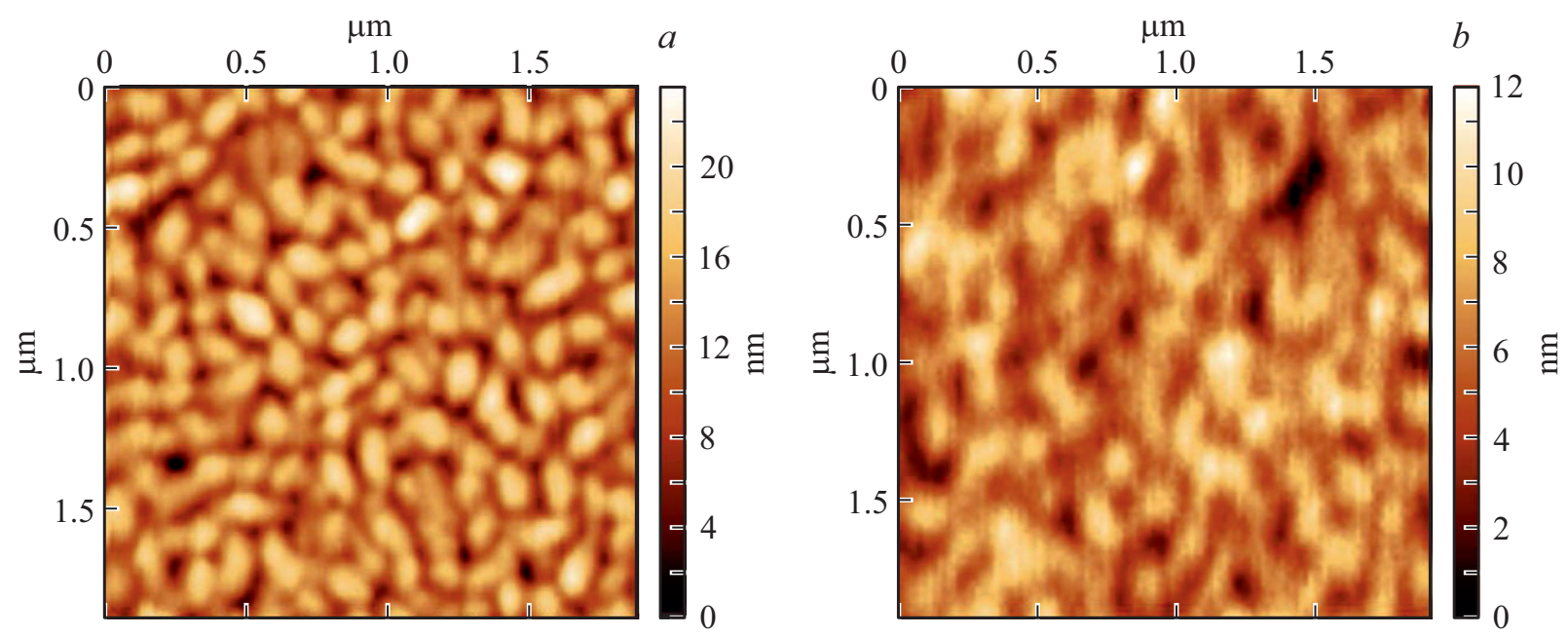

Рис. 2. Топографические АСМ-изображения поверхности кристаллической пленки пентацена перед обработкой $(a)$ и после отжига при $150^{\circ} \mathrm{C}(b)$.

рабатывались и анализировались с помощью программы Gwyddion [17].

Передаточные и выходные вольт-амперные характеристики $(\mathrm{BAX})$ устройств ОПТ исследовались по схеме с общим истоком с помощью источникаизмерителя 2612В (Keithley, США) и ПО Probestation („Принтэлтех“, Россия) [18] на зондовой станции LA150DC (Semiprobe, CША) при комнатной температуре. Подвижность носителей заряда $\mu$ в режиме насыщения определялась на основе полученных при измерении передаточных BAX зависимостей значений тока между истоком и стоком $I_{s d}$ от напряжения на затворе $U_{g}$ с помощью следующего выражения $[11,15]$ :

$$
I_{s d}=\frac{W}{2 L} \mu C\left(U_{g}-U_{T}\right)^{2},
$$

где $W$ и $L-$ ширина и длина канала транзистора соответственно, $C=7.3 \mathrm{nF} / \mathrm{cm}^{2}-$ удельная поверхностная электроемкость подзатворного диэлектрика (для оценки $C$ использовались значения диэлектрических проницаемостей $\left.\varepsilon_{\mathrm{SiO}_{2}}=3.9, \varepsilon_{\mathrm{PMMA}}=3.6\right)$. Ширина канала $W$ на различных образцах составляла 1,2 и $3 \mathrm{~mm}$, а длина канала $L$ была равна 100, 200 и $300 \mu \mathrm{m}$ соответственно, так что отношение $W / L$ во всех случаях составляло 10 .

Отжиг образцов проводился в течение $15 \mathrm{~h}$ при $150^{\circ} \mathrm{C}$ в потоке смеси аргона с 5\% водорода (НИИ КМ, Москва). Контроль расхода газа на уровне $0.31 / \mathrm{h}$ поддер- живался с помощью контроллера-расходомера EL-FLOW Prestige FG-200CV (Bronkhorst, Нидерланды).

Средние значения дырочной подвижности $\mu$ в режиме насыщения и порогового напряжения $U_{t}$ для серии из 20 полевых транзисторов, определенные до и после отжига, представлены в таблице. Установленные в наших условиях электрические характеристики пленок пентацена до обработки близки к исходным значениям, полученным в работе [11]. Как видно из таблицы, изотермический отжиг при $150^{\circ} \mathrm{C}$ в течение $15 \mathrm{~h}$ привел к увеличению средней дырочной подвижности на $30 \%$ и снижению порогового напряжения приблизительно в 2 раза. В качестве примера на рис. 1 приведены передаточные $(a)$ и выходные $(b)$ ВАХ одного из образцов. Для данного транзистора подвижность возросла в 1.4 раза (c $2.1 \cdot 10^{-3}$ до $2.9 \cdot 10^{-3} \mathrm{~cm}^{2} \cdot \mathrm{V}^{-1} \cdot \mathrm{s}^{-1}$ ), а абсолютное значение порогового напряжения снизилось с 13.4 до $9.9 \mathrm{~V}$. Судя по изменениям выходных характеристик в линейной области (см. вставку на рис. $1, b$ ), отжиг привел к снижению контактного барьера на границе пленки Рс с золотыми электродами.

По данным АCM толщина пленок Рс в результате термической обработки изменилась незначительно, а морфология поверхности и зеренная структура претерпели существенные изменения (рис. 2). Как видно из представленных на рис. 2 топографических АСМ-изображений поверхности пленки пентацена, отжиг привел к 
снижению средней шероховатости поверхности $R_{a}$ более чем в 2 раза и укрупнению зерен вместе с некоторым размытием межзеренных границ (средняя плотность зерен $N_{a}$ уменьшилась почти в 2 раза), см. таблицу.

Таким образом, улучшение электрических свойств напыленных кристаллических пленок пентацена и снижение контактного барьера на границе с электродами стока и истока связаны со структурной перестройкой молекул в процессе отжига в инертной атмосфере. Судя по увеличению дырочной подвижности $\mu$ и снижению порогового напряжения полевых транзисторов, отжиг пленок снизил число ловушек для электротранспорта в канале транзистора, что, согласно данным АСМ, отчасти связано с укрупнением зерен и повышением их связности (рис. 2). В дальнейшем запланированы поиск оптимальных параметров термовременной обработки и выяснение роли буферного диэлектрика - РММА в процессах рекристаллизации пентацена, приводящих к значительному улучшению электрических характеристик тонкопленочных полевых транзисторов.

\section{Финансирование работы}

Работа выполнена при поддержке Министерства науки и высшего образования РФ в рамках государственного задания ФНИЦ „Кристаллография и фотоника“ РАН с использованием научного оборудования ЦКП „Структурная диагностика материалов“ (проект RFMEF162119X0035).

\section{Конфликт интересов}

Авторы заявляют, что у них нет конфликта интересов.

\section{Список литературы}

[1] В.Д. Александров, Высокомолекуляр. соединения А, 20 (9), 1943 (1978).

[2] S. Kania, W. Mycielski, A. Lipiński, Thin Solid Films, 61 (2), 229 (1979). DOI: 10.1016/0040-6090(79)90465-6

[3] M.A. Fusella, S. Yang, K. Abbasi, H.H. Choi, Z. Yao, V. Podzorov, A. Avishai, B.P. Rand, Chem. Mater., 29 (16), 6666 (2017). DOI: 10.1021/acs.chemmater.7b01143

[4] Y. Jin, Z. Rang, M.I. Nathan, P.P. Ruden, C.R. Newman, C.D. Frisbie, Appl. Phys. Lett., 85 (19), 4406 (2004). DOI: $10.1063 / 1.1814802$

[5] X. Shen, Y. Wang, J. Li, Y. Chen, Z. Wang, W. Wang, L. Huang, L. Chi, Front. Mater., 7, 245 (2020). DOI: $10.3389 /$ fmats.2020.00245

[6] D. Guo, S. Ikeda, K. Saiki, J. Appl. Phys., 99 (9), 094502 (2006). DOI: 10.1063/1.2193055

[7] D. Guo, S. Ikeda, K. Saiki, J. Appl. Phys., 105 (11), 113520 (2009). DOI: $10.1063 / 1.3132824$

[8] T. Ahn, H. Jung, H.J. Suk, M.H. Yi, Synth. Met., 159 (13), 1277 (2009). DOI: 10.1016/j.synthmet.2009.02.023

[9] D.W. Chou, C.J. Huang, C.M. Su, C.F. Yang, W.R. Chen, T.H. Meen, Solid State Electron., 61 (1), 76 (2011). DOI: $10.1016 /$ j.sse.2011.01.003
[10] H.S. Shin, H.J. Yun, K.H. Baek, Y.H. Ham, K.S. Park, D.P. Kim, G.W. Lee, H.D. Lee, K. Lee, L.M. Do, J. Nanosci. Nanotechnol., 12 (7), 5325 (2012). DOI: $10.1166 /$ jnn.2012.6253

[11] Lassnig, B. Striedinger, M. Hollerer, A. Fian, B. Stadlober, A. Winkler, J. Appl. Phys., 116 (11), 114508 (2014). DOI: $10.1063 / 1.4895992$

[12] Y.J. Lin, H.Y. Tsao, Microelectron. Eng., 149 (C), 57 (2016). DOI: 10.1016/j.mee.2015.09.014

[13] T. Siegrist, C. Besnard, S. Haas, M. Schiltz, P. Pattison, D. Chernyshov, B. Batlogg, C. Kloc, Adv. Mater., 19 (16), 2079 (2007). DOI: 10.1002/adma.200602072

[14] S. Jo, M. Takenaga, Jpn. J. Appl. Phys., 49 (7R), 078002 (2010). DOI: 10.1143/JJAP.49.078002

[15] A. Tsumura, H. Koezuka, T. Ando, Appl. Phys. Lett., 49 (18), 1210 (1986). DOI: 10.1063/1.97417

[16] L.G. Kudryashova, M.S. Kazantsev, V.A. Postnikov, V.V. Bruevich, Y.N. Luponosov, N.M. Surin, O.V. Borshchev, S.A. Ponomarenko, M.S. Pshenichnikov, D.Y. Paraschuk, ACS Appl. Mater. Interfaces, 8 (16), 10088 (2016). DOI: $10.1021 /$ acsami.5b11967

[17] P. Nečas, D. Klapetek, Gwiddion software [Электронный pecypc]. URL: http://gwyddion.net/

[18] D. Zotkin, A. Sizov, Probestation software: 1.13. 